\title{
Cigarette Mouth Insertion Depths Among Chinese Smokers*
}

\author{
by \\ Qun Hu, Zhihua Liu, Jing Ma, Lijuan Peng, and Haijun Bai \\ Yunnan Academy of Tobacco Science, Kunming 650106, P.R.China
}

\section{SUMMARY}

Vent blocking - where filter ventilation holes are intentionally or unintentionally, partly or completely covered by smokers' lips during smoking - is an aspect of smoking behavior which can alter mainstream smoke yields. This study was designed to determine if, and to what extent ventilation holes were blocked by smokers' lips in two cohorts of Chinese smokers. In this study, two groups of samples were collected. One group (1742 butts) was collected randomly from public places in six chosen cities. Another (1037 butts) was obtained by collecting the butts from identified smokers in Kunming. In this paper, the mouth insertion depth among Chinese smokers was studied for the first time by a staining method employing ninhydrin in ethanol.

The results indicate that Chinese smokers exhibit a mouth insertion depth ranging from 1 to $17 \mathrm{~mm}$ with an average value of $7.5 \pm 2 \mathrm{~mm}$. In this study, $95 \%$ of the ventilated filters examined showed that the vent zone was neither completely nor partially covered by smokers' lips. [Beitr. Tabakforsch. Int. 20 (2003) 476-480]

\section{ZUSAMMENFASSUNG}

Das absichtliche oder zufällige, teilweise oder vollständige Abdecken der Filterventilationslöcher durch die Lippen des Rauchers beim Rauchen einer Zigarette ist ein Aspekt des Rauchverhaltens, der Einfluss auf die Ausbeute an Hauptstromrauchinhaltsstoffen haben kann. Diese Studie wurde durchgeführt um festzustellen, ob und in welchem Ausmaß die Ventilationslöcher bei zwei Kohorten chinesischer Raucher durch die Lippen der Raucher abgedeckt werden. Bei dieser Untersuchung wurden zwei Arten von Proben gesammelt. Der eine Teil (1742 Stummel) wurde zufällig von öffentlichen Plätzen in sechs ausgewählten Städten aufgesammelt, der andere Teil (1037 Stummel) stammte von vorher bestimmten Rauchern aus Kunming. Die Einstecktiefe der Zigaretten bei chinesischen Rauchern wurde zum ersten Mal mit Hilfe einer alkoholischen Ninhydrin-Lösung bestimmt, wodurch Speichelabdrücke sichtbar gemacht wurden.

Die Ergebnisse zeigen, dass die Einstecktiefe bei chinesischen Rauchern zwischen 1 und $17 \mathrm{~mm}$ liegt und durchschnittlich 7,5 $\pm 2 \mathrm{~mm}$ beträgt. Bei $95 \%$ der untersuchten ventilierten Filter war die Ventilationszone weder vollständig noch teilweise durch die Lippen des Rauchers abgedeckt. [Beitr. Tabakforsch. Int. 20 (2003) 476-480]

\section{RESUME}

L' obstruction, intentionnelle ou accidentelle, des trous de ventilation, de façon partielle ou complète, par les lèvres des fumeurs en cours du fumage est un aspect du mode de fumage qui pourrait avoir une influence sur le rendement en composants de la fumée du courant principal. L' objectif de cette étude était d' examiner dans quelle mesure les trous de ventilation étaient obstrués par les lèvres des fumeurs chez deux cohortes de fumeurs chinois. Dans cette étude, deux types d' échantillons ont été recueillis. Une partie (1742 mégots) a été recueillie au hasard sur des places publiques de six villes choisies. Une autre partie (1037 mégots) a été recueillie de fumeurs choisis de Kunming. La profondeur d' insertion de la cigarette chez les fumeurs chinois, a pour la première fois, été déterminées par une solution alcoolique de ninhydrine, pour visualiser les taches de salive.

Les résultats indiquent que les fumeurs chinois ont une profondeur d' insertion de 1 à $17 \mathrm{~mm}$ avec une profondeur d' insertion moyenne de 7,5 $\pm 2 \mathrm{~mm}$. Dans cette étude, $95 \%$ des filtres ventilés examinés ne démontrent aucune trace d' obstruction complète ou partielle des orifices par les lèvres des fumeurs. [Beitr. Tabakforsch. Int. 20 (2003) 476-480] 
Table 1. Description of all samples

\begin{tabular}{lcc|c|c}
\hline Samples & Collected & Experimental & Measurable & $\begin{array}{c}\text { Insertion depth } \\
(\mathrm{mm} \pm \text { std. dev })\end{array}$ \\
\hline Collected randomly & 1742 & $1673(96 \%)$ & $1338(77 \%)$ & $7.4 \pm 1.8$ \\
Butts returned & 1037 & $900(87 \%)$ & $780(75 \%)$ & $7.7 \pm 2.4$ \\
Sum & $\mathbf{2 7 7 9}$ & $\mathbf{2 5 7 3 ( 9 3 \% )}$ & $\mathbf{2 1 1 8}(\mathbf{7 6 \% )}$ & $\mathbf{7 . 5 \pm 2 . 0}$ \\
\hline
\end{tabular}

\section{INTRODUCTION}

Vent blocking - where filter ventilation holes are covered intentionally or unintentionally during smoking - is an aspect of smoking behavior which may increase mainstream smoke yields (2,3-6). Studies on cigarette mouth insertion depth distribution among smokers have been undertaken between 1974 and 1997 in Germany, Switzerland, UK, USA and Canada to determine if, and to what extent the vent zone was blocked by smokers' lips (1-8). In these studies, mouth insertion depths were measured by a distinct color which was produced by reaction of a reagent with dried saliva residues on the cigarette butts. For example, amino acids in dried saliva on the tipping papers reacting with ninhydrin form a pink coloration. Insertion depths ranging from 3 to $25 \mathrm{~mm}$ with means of 10.1 to 11.5 $\mathrm{mm}$ were obtained and it was concluded that ventilation hole coverage by lips during smoking depended on the position of the ventilation zone (1-8).

In this paper, the mouth insertion depth among Chinese smokers was examined for the first time by a staining method employing ninhydrin in ethanol.

\section{EXPERIMENTAL DETAILS}

\section{Sample collection}

The samples were divided into two groups. One group was collected from unidentified ashtrays in offices and public places, such as department stores, bars, governmental buildings, schools, and meeting rooms in hospitals and factories from six cities in China, including Kunming, Yuxi, Guangzhou, Zhengzhou, Xining and Beijing, and 1742 butts were collected. The other group was obtained by collecting butts from smokers in Kunming, such as civil servants, teachers, doctors and physical laborers who were selected randomly.

Using the "Diaoyutai" brand (flue-cured cigarettes produced by Yunnan Academy of Tobacco Science), 800 non-ventilated and 800 ventilated cigarettes (laser pre-perforated tipping, the positions of two rings of ventilation holes were 13 and $15 \mathrm{~mm}$, respectively, from the mouth end of the filter) were distributed to the smokers and were smoked during two weeks. The selected smokers were not told about the purpose of this study. A total of 1037 butts was returned, but many were obviously lost and ended up in litter. There were no significant differences in the location of ventilation zones in the butts collected in Kunming and other cities in this study.

\section{Selected method}

Historically, a $4 \%$ aqueous solution of ninhydrin has been used to react with amino acids in the dried saliva on the tipping paper to produce a lip imprint as a pink coloration $(2,3)$. In this research, a $4 \%$ ethanol solution of ninhydrin was used to react with amino acids in the dried saliva on the tipping papers.

\section{Determination of insertion depth}

The tipping paper was removed from the filter and numbered within its group. Then the resultant tipping was fixed on a glass plate $(700 \times 600 \mathrm{~mm}), 150$ at a time. They were sprayed to saturation with $4 \%(\mathrm{w} / \mathrm{w})$ ethanol solution of ninhydrin. Then, the saturated tipping papers were placed in a room under ambient temperature $\left(18 \pm 6{ }^{\circ} \mathrm{C}\right)$ for $48 \mathrm{~h}$ and a sinusoidal-shaped, purple imprint would appear on the paper (corresponding to the residual traces of saliva). The distance in $\mathrm{mm}$ between the mouth end of the tipping and the most distinct evidence of the lip imprint was measured and defined as the maximum insertion depth of the butt. The length and width of the finger imprints were also measured for evaluating the possibility of vent blocking by fingers. The stains made by lips were continuous imprints, but those made with fingers were separated stains. Data analysis was done with Microsoft Excel.

\section{RESULTS AND DISCUSSION}

\section{Insertion depth data analysis}

As shown in Table 1, a total of 2779 butts was collected in this research. However, $7 \%$ of them were contaminated or destroyed while $93 \%$ (2573 butts) were regarded as viable experimental samples; $76 \%$ of butts collected produced measurable lip imprints with the ninhydrin method.

The collected filter samples, either ventilated or non-ventilated, came from different smokers of different cities in China, the differences of the resulting measurements are of no relevance for the aim of the study (Tables 1, 2 and 3). The frequency distribution of different insertion depths is summarized in Figures 1 and 2. The results of distribution of all samples are shown in Tables 2 and 3.

There appears to be a difference between the average insertion depths of Chinese smokers (1-17 $\mathrm{mm}$ ) and foreign smokers (3-25 mm), which probably is due to different human race and smoking behaviors. 
Table 2. Samples collected randomly from different cities in China

\begin{tabular}{lcc|c|c}
\hline City & Collected & Experimental & Measurable & $\begin{array}{c}\text { Insertion depth } \\
(\mathrm{mm} \pm \text { std. dev.) }\end{array}$ \\
\hline Kunming & 305 & $300(98 \%)$ & $238(78 \%)$ & $7.9 \pm 2.4$ \\
Yuxi & 300 & $289(96 \%)$ & $231(77 \%)$ & $7.6 \pm 2.2$ \\
Xining & 294 & $285(97 \%)$ & $226(77 \%)$ & $7.7 \pm 2.1$ \\
Beijing & 280 & $264(94 \%)$ & $213(76 \%)$ & $7.6 \pm 2.0$ \\
Zhengzhou & 290 & $273(94 \%)$ & $219(76 \%)$ & $7.6 \pm 2.0$ \\
Guangzhou & 273 & $262(96 \%)$ & $211(77 \%)$ & $7.5 \pm 1.9$ \\
Sum & $\mathbf{1 7 4 2}$ & $\mathbf{1 6 7 3 ( 9 6 \% )}$ & $\mathbf{1 3 3 8 ( 7 7 \% )}$ & $\mathbf{7 . 7 \pm 1 . 8}$ \\
\hline
\end{tabular}

Table 3. Samples collected by returning cigarettes distributed

\begin{tabular}{|c|c|c|c|c|}
\hline Kunming & Returned & Experimental & Measurable & $\begin{array}{l}\text { Insertion depth } \\
\text { (mm } \pm \text { std. dev.) }\end{array}$ \\
\hline Ventilated & 520 & 461 (89\%) & $393(76 \%)$ & $7.6 \pm 2.5$ \\
\hline Non-ventilated & 517 & $439(85 \%)$ & $387(75 \%)$ & $7.8 \pm 2.4$ \\
\hline Sum & 1037 & 900 (87\%) & 780 (75\%) & $7.7 \pm 2.4$ \\
\hline
\end{tabular}

\section{Discussion on vent blocking}

The position of ventilation holes in Chinese cigarettes with static perforation is usually between 13 and $17 \mathrm{~mm}$ from the mouth end. In laser-perforated cigarettes, two rings of holes are usually positioned at 13 and $15 \mathrm{~mm}$. There are two possible ways to block ventilation if it occurs at all. One is mouth insertion depth, and the other is vent blocking by the fingers.

1. Insertion depth: All cigarettes used in this study had ventilation holes applied with laser perforation technology which is more often used in China than static perforation. The perforation ranged from 13 to $15 \mathrm{~mm}$. As reported previously (2), insertion depth measurements can only be used to estimate maximum lip blockage. Using the calculation method reported (2) results in the proportion of blocked vents shown in Table 4 . When the average insertion depth measured (three measurements per cigarette) was greater than the maximum distance from the cigarette mouth end to the far edge of the ventilation zone $(\geq 15 \mathrm{~mm})$, the ventilation zone was regarded as completely covered by the lips. When the average insertion depth measured was between the maximum and minimum distance of the mouth end to the edge of the ventilation zone $(13-15 \mathrm{~mm})$, the ventilation zone was considered partially covered by the lips. When the average insertion depth measured was less than the minimum distance from the cigarette mouth end to the edge of the ventilation zone $(<13 \mathrm{~mm})$, the ventilation zone obviously was not covered by the lips.

Based on the insertion depths measured, vent blocking by mouth coverage was not as prevalent as that reported by KOZLOWSKI. The reported degrees of partial or complete vent blocking were in the range of 32-69\% (3-7). Table 4 shows there is minimal vent blocking by the lips among Chinese smokers (approx. 5\%).
2. Effect of fingers: In this research, clear fingerprints were observed as imprints on the tipping papers, which did not overlap. About $20 \%$ of them were found extending into the perforation areas. However, it is impossible to determine when the fingerprints were left on the cigarettes, either while smoking or during the puff intervals. No differences between ventilated and non-ventilated cigarettes were observed. It is not possible to know if a cigarette being smoked was held by the fingers in such a way that the vent zone was partially blocked.

\section{CONCLUSION}

In this study, the mouth insertion depths among Chinese smokers were for the first time demonstrated by a method in which the saliva-stained tipping papers of cigarette butts were treated with a $4 \%(\mathrm{w} / \mathrm{w})$ ethanol solution of ninhydrin. The results indicate that Chinese smokers exhibit mouth insertion depths ranging from 1 to $17 \mathrm{~mm}$ with an average value of $7.5 \pm 2.0 \mathrm{~mm}$. There was no significant difference in the mouth insertion depths among smokers in different regions of China, and there was also no significant difference between the mouth insertion depths of ventilated (7.6 $\pm 2.5 \mathrm{~mm})$ and non-ventilated cigarettes $(7.8 \pm 2.4 \mathrm{~mm})$. Ninety-five percent of the ventilated filters examined showed no vent zone blockage by smokers' lips, only $4 \%$ showed some coverage and only $1 \%$ showed complete coverage.

\section{ACKNOWLEDGEMENT}

We wish to thank Cui Diou, Duan Hong, He Wei, Li Zhongjun, Wan Shanhong and Fang Hua, who are from Beijing, Zhenhzhou, Xining, Guangzhou, Yuxi and Kunming, respectively, for their valuable assistance in collecting cigarette butts in public places. 

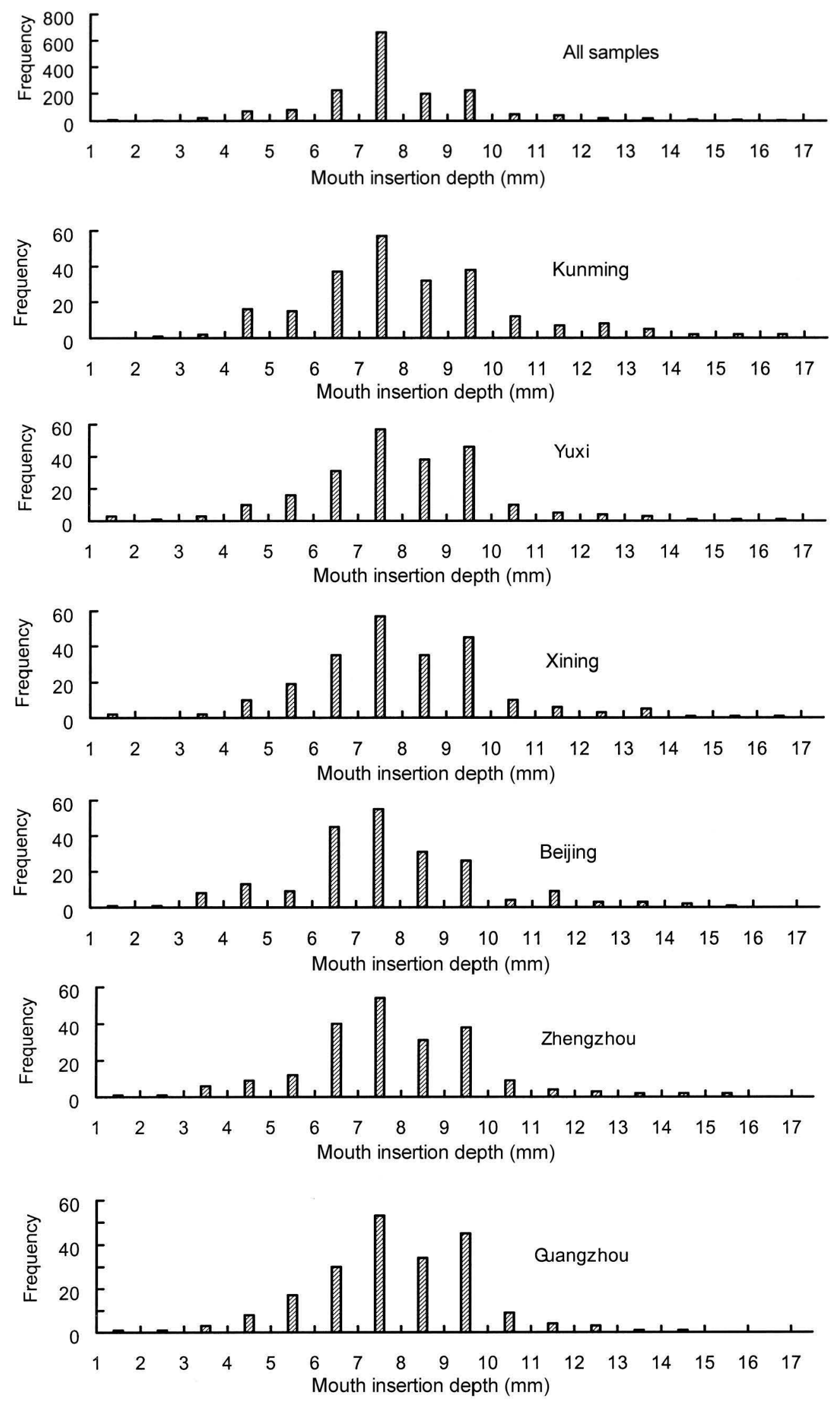

Figure 1. Distribution of maximum insertion depths of randomly collected samples 

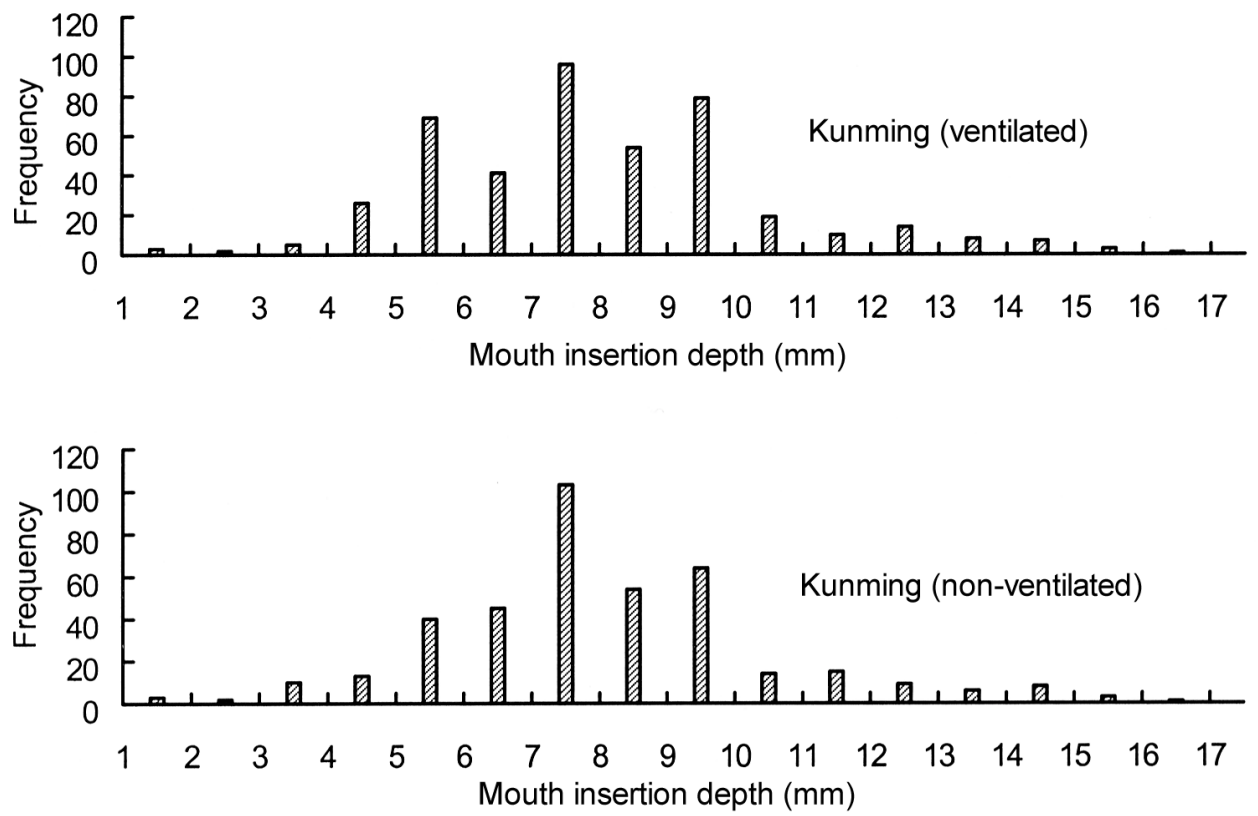

Figure 2. Distribution of maximum insertion depths of returned samples

Table 4. Proportion of blocked vents $(N=393$ measurable samples, Table 3)

\begin{tabular}{lcc}
\hline Coverage & Frequency & Percent \\
\hline Complete coverage $(\geq 15 \mathrm{~mm})$ & 4 & 1.0 \\
Partial coverage $(13-15 \mathrm{~mm})$ & 15 & 3.8 \\
No coverage $(<13 \mathrm{~mm})$ & 374 & 95.2 \\
\hline
\end{tabular}

\section{REFERENCES}

1. Baker, R.R., M. Dixon, and C.A. Hill: Measurement of mouth insertion depths amongst British smokers; paper presented at the CORESTA Smoke and Technology Groups' Joint Meeting, Hamburg, Germany, September 1997; The incidence and consequences of filter vent blocking amongst British smokers; Beitr. Tabakforsch. Int. 18 (1998) 71-83.

2. Baker, R.R. and L.S. Lewis: Ventilation - has there been a "Cover-up"?; Rec. Adv. Tob. Sci. 23 (1997)152-196.

3. Kozlowski, L.T., M.A. Pope, and J.E. Lux: Prevalence of the misuse of ultra-low-tar cigarettes by blocking filter vents; Am. J. Public Health 78 (1998) 694-695.

4. Kozlowski, L.T., J.L. Pillitteri, and C.T. Sweeney: Misuse of "light" cigarettes by means of vent blocking; J. Substance Abuse 6 (1994) 333-336.

5. Kozlowski, L.T., R.C. Frecker, V. Khouw, and M.A. Pope: The misuse of "less-hazardous" cigarettes and its detection: hole-blocking of ventilated filters; Am. J. Public Health 70 (1980) 1202-1203.
6. Kozlowski, L.T., W.S. Rickert, M.A. Pope, J.C. Robinson, and R.C.Frecker: Estimating the yield to smoker of tar, nicotine, and carbon monoxide from the "lowest yield" ventilated filter-cigarettes; Brit. J. Addiction 77 (1982) 159-165.

7. Kozlowski, L.T. and C.T. Sweeney: Low-yield, light and ultra-light cigarettes: Let's understand the product before we promote; in: Social marketing: theoretical and practical perspectives, edited by M.E. Goldberg, M. Fishbein, and S.E. Middlestadt, Lawrence Erlbaum Associates, Mahwah, New Jersey, USA, 1997, pp. 231-244.

8. Porter, A.R. and P.J. Dunn: Mouth insertion depths in Canadian smokers; paper presented at the CORESTA Smoke and Technology Groups' Joint Meeting, Hamburg, Germany, September 1997; Beitr. Tabakforsch. Int. 18 (1998) 85-91.

Address for correspondence

Hu Qun

Yunnan Academy of Tobacco Science

Research Group of Cigarette Supplementary Material

41 Keyi Road

Kunming 650106

P.R.China

Email:Huqun@cyats.ytt.com.cn 